Article

\title{
Anticancer Effect of Ursodeoxycholic Acid in Human Oral Squamous Carcinoma HSC-3 Cells through the Caspases
}

\section{Liang Pang ${ }^{1,2, \dagger}$, Xin Zhao ${ }^{3,4, \dagger}$, Weiwei Liu ${ }^{5, \dagger}$, Jiang Deng ${ }^{1,2}$, Xiaotong Tan ${ }^{6}$ and Lihua Qiu ${ }^{1,7, *}$}

1 Department of Oral and Maxillofacial Surgery, Stomatological Hospital of Chongqing Medical University, Chongqing 401147, China; E-Mails: pangliang@foods.ac.cn (L.P.); dengjiang@foods.ac.cn (J.D.)

2 Chongqing Key Laboratory for Oral Diseases and Biomedical Sciences, Chongqing 401147, China

3 Department of Biological and Chemical Engineering, Chongqing University of Education, Chongqing 400067, China; E-Mail: zhaoxin@cque.edu.cn

4 Institute of Functional Ecological Food, Chongqing University of Education, Chongqing 400067, China

5 School of Public Health and Management, Chongqing Medical University, Chongqing 400016, China; E-Mail: weiweiliu521@gmail.com

6 Department of Food Science and Nutrition, Pusan National University, Busan 609-735, Korea; E-Mail: tanxiaotong@pusan.ac.kr

7 Chongqing Municipal Key Laboratory of Oral Biomedical Engineering of Higher Education, Chongqing 401147, China

$\dagger$ These authors contributed equally to this work.

* Author to whom correspondence should be addressed; E-Mail: cqqiulh@gmail.com; Tel./Fax: +86-23-6752-6063.

Received: 8 January 2015 / Accepted: 22 April 2015 / Published: 5 May 2015

\begin{abstract}
Bear bile was used as a traditional medicine or tonic in East Asia, and ursodeoxycholic acid (UDCA) is the most important compound in bear bile. Further, synthetic UDCA is also used in modern medicine and nutrition; therefore, its further functional effects warrant research, in vitro methods could be used for the fundamental research of its anticancer effects. In this study, the apoptotic effects of UDCA in human oral squamous carcinoma HSC-3 cells through the activation of caspases were observed by the experimental methods of MTT (3-(4,5-dimethyl-2-thiazolyl)-2,5-diphenyl-2- $H$-tetrazolium bromide) assay, DAPI (4',6-diamidino-2-phenylindole) staining, flow cytometry analysis, RT-PCR (reverse transcription-polymerase chain reaction) assay and Western blot assay
\end{abstract}


after HSC-3 cells were treated by different concentrations of UDCA. With 0 to $400 \mu \mathrm{g} / \mathrm{mL}$ UDCA treatment, UDCA had strong growth inhibitory effects in HSC-3 cells, but had almost no effect in HOK normal oral cells. At concentrations of 100, 200 and $400 \mu \mathrm{g} / \mathrm{mL}$, UDCA could induce apoptosis compared to untreated control HSC-3 cells. Treatment of $400 \mu \mathrm{g} / \mathrm{mL}$ UDCA could induce more apoptotic cancer cells than 100 and $200 \mu \mathrm{g} / \mathrm{mL}$ treatment; the sub-G1 DNA content of $400 \mu \mathrm{g} / \mathrm{mL}$ UDCA treated cancer cells was $41.3 \%$ versus $10.6 \%$ $(100 \mu \mathrm{g} / \mathrm{mL})$ and $22.4 \%(200 \mu \mathrm{g} / \mathrm{mL})$. After different concentrations of UDCA treatment, the mRNA and protein expressions of caspase-3, caspase-8, caspase-9, Bax, Fas/FasL (Fas ligand), TRAIL (TNF-related apoptosis-inducing ligand), DR4 (death receptor 4) and DR5 (death receptor 5) were increased in HSC-3 cells, and mRNA and protein expressions of Bcl-2 (B-cell lymphoma 2), Bcl-xL (B-cell lymphoma-extra large), XIAP (X-linked inhibitor of apoptosis protein), cIAP-1 (cellular inhibitor of apoptosis 1), cIAP-2 (cellular inhibitor of apoptosis 2) and survival were decreased. Meanwhile, at the highest concentration of $400 \mu \mathrm{g} / \mathrm{mL}$, caspase-3, caspase-8, caspase-9, Bax, Fas/FasL, TRAIL, DR4,

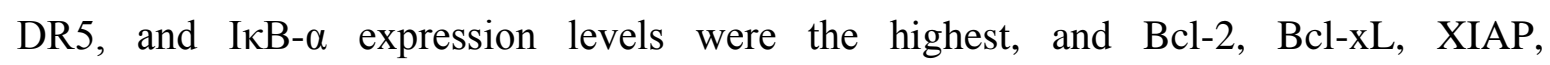
cIAP-1, cIAP-2, survival, and NF- $\kappa B$ expression levels were the lowest. These results proved that UDCA could induce apoptosis of HSC-3 cancer cells through caspase activation, and the higher concentration of UDCA had stronger effects in vitro. UDCA might be a good nutrient for oral cancer prevention.

Keywords: ursodeoxycholic acid; human oral squamous carcinoma HSC-3 cells; apoptosis; caspase; expression

\section{Introduction}

In traditional Asian medicine, bear bile extracted from the gallbladder of Ursus thibetanus or Ursus arctos is considered a cure for various diseases. With the development of modern medicine, it is found that the major active component in bear bile is ursodeoxycholic acid (UDCA) [1]. Nowadays, synthetic UDCA is a safe drug with no side effects and is widely used in the treatment of diseases, such as gallstones, primary cirrhosis, autoimmune hepatitis and colon cancer around the world [2].

Oral cancers are common malignant tumors in the head and neck and are mostly categorized as squamous cell carcinomas, in which the mucous membranes in the gum, tongue, and face transform and progress to cancer [3]. There are many causes of oral cancers, including poor oral hygiene caused by bad living habits and chronic ulcers in gum tissue. Due to the long-term intake of a high-fat, high-protein, and low-cellulose diet, each organ in the digestive system functions abnormally, producing a large amount of harmful bacteria leading to a large number of harmful bacteria growing in the mouth, which produce carcinogens that cause oral cancers [4]. Chronic inflammation, from, for example, gingivitis and periodontitis, may be another cause of oral cancer [5]. Written in ancient Chinese medical books, bear bile can treat bacterial diseases through sterilization. Laboratory experiments further confirmed that the main component of bear bile, UDCA, has the effect of sterilization and inhibition of inflammation [1]. Bamboo salt UDCA toothpastes appear on the market in China and South Korea, and clinical surveys 
prove that UDCA can prevent gum and periodontal problems and reduce gum bleeding. Therefore, UDCA may be useful in treating oral cancers.

Inducing cancer cell apoptosis is one way to control cancer, so it is beneficial for the treatment of oral cancers to increase activation, expression, and regulation of caspase family genes leading to death of oral cancer cells [6]. Although the detailed mechanism of apoptosis is not entirely clear, it has been identified that caspases play an indispensable role in apoptosis. The apoptotic process is actually the cascading amplification of caspase hydrolysis of their substrates [7]. Using UDCA to strengthen caspase activity may be a new way for the treatment of oral cancers by inducing apoptosis of oral cancer cells. In this study, through using UDCA treatment in vitro on cultured cancer cells, changes in caspase gene expression of cancer cells are detected and the effect of UDCA on inducing cancer cell apoptosis is observed.

\section{Materials and Methods}

\subsection{Preparations of Ursodeoxycholic Acid (UDCA)}

UDCA monomer was purchased from Shanghai Ekear Biotechnology Co. Ltd. (Shanghai, China), chenodeoxycholic acid (CDCA) monomer was purchased from Nanjing Senbeijia Biological Technology Co. Ltd. (Nanjing, China) and deoxycholic acid (DCA) monomer was purchased from Shanghai Pureone Biotechnology Co. Ltd. (Shanghai, China).

\subsection{Cell Preparation}

Human oral squamous carcinoma HSC-3 cells were obtained from American Type Culture Collection (Manassas, VA, USA), TCA8113 human tongue carcinoma cells obtained from Shanghai Institute of Biochemistry and Cell Biology (Shanghai, China) and HOK normal oral epithelial cells were obtained from ScienCell Research Laboratories (Carlsbad, CA, USA). These cells were cultured in DMEM medium (Thermo Fisher Scientific Inc.; Waltham, MA, USA) supplemented with $10 \%$ fetal bovine serum (FBS) and 1\% penicillin-streptomycin (Gibco-BRL; Grand Island, NY, USA) at $37{ }^{\circ} \mathrm{C}$ in a humidified atmosphere with 5\% $\mathrm{CO}_{2}$ (incubator model 311 S/N29035; Forma, Waltham, MA, USA). The medium was changed 2-3 times a week [8].

\subsection{3-(4,5-Dimethyl-2-Thiazolyl)-2,5-Diphenyltetrazolium Bromide (MTT) Assay}

Growth of HSC-3, TCA8113 and HOK cells after UDCA, CDCA and DCA treatment were assessed by the MTT assay. UDCA, CDCA and DCA were added to the DMEM medium, the UDCA, CDCA and DCA culture medium solutions were made at concentrations of $0-500 \mu \mathrm{g} / \mathrm{mL}$. HSC-3 and HOK cells were seeded in 96 well plates at a density of $1 \times 10^{5}$ cells $/ \mathrm{mL}$ in each well $(100 \mu \mathrm{L})$ and incubated at $37{ }^{\circ} \mathrm{C}$ in $5 \% \mathrm{CO}_{2}$. After $24 \mathrm{~h}$ culture, the culture medium was aspirated and discarded from each well, then the UDCA, CDCA and DCA containing culture medium was added to each well, then incubated for $48 \mathrm{~h}$. The culture medium was aspirated and discarded in each well again, then the $5 \mathrm{mg} / \mathrm{mL}$ MTT solution (Amresco; Solon, OH, USA) was added in each well $(100 \mu \mathrm{L})$ and the cells were cultured for $4 \mathrm{~h}$. Following removal of the MTT solution, $100 \mu \mathrm{L}$ DMSO was added to each well and mixed for 
30 min. Subsequently, the absorbance of each well was measured with an enzyme-linked immunosorbant assay (ELISA) reader (model 680; Bio-Rad; Hercules, CA, USA) at $490 \mathrm{~nm}$ [9].

\subsection{Nuclear Staining with 4',6-Diamidino-2-Phenylindole (DAPI)}

HSC-3 cell solution ( $2 \mathrm{~mL}$ ) was added to a $10 \mathrm{~cm}$ culture dish and incubated at $37{ }^{\circ} \mathrm{C}$ in $5 \% \mathrm{CO}_{2}$ for $24 \mathrm{~h}$. Then the culture medium was aspirated and discarded, followed by addition of the UDCA culture medium solutions (100, 200 and $400 \mu \mathrm{g} / \mathrm{mL}$ ) and cultured for $48 \mathrm{~h}$. UDCA untreated control cells and cells treated with the UDCA were harvested, washed with PBS twice, and fixed with 3.7\% paraformaldehyde (Sigma; St. Louis, MO, USA) in PBS for $10 \mathrm{~min}$ at $25^{\circ} \mathrm{C}$. The fixed cells were washed with PBS and stained with $1 \mathrm{mg} / \mathrm{mL}$ DAPI (Sigma) solution for $10 \mathrm{~min}$. The cells were washed 3 times with PBS and examined with a fluorescence microscope (BX50; Olympus, Tokyo, Japan) [10].

\subsection{Flow Cytometry Analysis}

After treatment with DAPI for the first $72 \mathrm{~h}$, the cells were trypsinized, collected, washed with cold PBS, and resuspended in $2 \mathrm{~mL}$ PBS. DNA content of the cells were measured using a DNA staining kit (CycleTESTTM PLUS kit; Becton Dickinson, Franklin Lakes, NJ, USA). Nuclear fractions stained with propidium iodide were obtained by following the manufacturer's protocol. Fluorescence intensity was determined using the FACScan flow cytometer (EPICS XL-MCL; Beckman Coulter KK, Brea, CA, USA) and analyzed with CellQuest software (Becton Dickinson) [7].

\subsection{RT-PCR Assay}

Total RNA from HSC-3 cells was isolated using Trizol reagent (Invitrogen; Carlsbad, CA, USA) according to the manufacturer's recommendations. The cancer cell RNA was digested with RNase-free DNase (Roche; Basel, Switzerland) for $15 \mathrm{~min}$ at $37^{\circ} \mathrm{C}$ and purified using the RNeasy kit (Qiagen; Hilden, Germany) according to the manufacturer's protocol. cDNA was synthesized from $2 \mu \mathrm{g}$ of total RNA by incubation at $37^{\circ} \mathrm{C}$ for $\mathrm{l} \mathrm{h}$ with avian myeloblastosis virus reverse transcriptase (GE Healthcare; Little Chalfont, United Kingdom) with random hexanucleotides according to the manufacturer's instruction. Sequences of primers used to specifically amplify the genes of interest are shown in Table 1 . Amplification was performed in a thermal cycler (Eppendorf; Hamburg, Germany). The polymerase chain reaction (PCR) products were separated in 1.0\% agarose gels and visualized with ethidium bromide staining [11]. 
Table 1. Sequences of reverse transcription-polymerase chain reaction primers were used in this study.

\begin{tabular}{|c|c|}
\hline Gene Name & Sequence \\
\hline \multirow{2}{*}{ Caspase-3 } & Forward: 5'-CAA ACT TTT TCA GAG GGG ATC G-3' \\
\hline & Reverse: 5'-GCA TAC TGT TTC AGC ATG GCA-3' \\
\hline \multirow{2}{*}{ Caspase-8 } & Forward: 5'-CCC CAC CCT CAC TTT GCT-3' \\
\hline & Reverse: 5'-GGA GGA CCA GGC TCA CTT A-3' \\
\hline \multirow{2}{*}{ Caspase-9 } & Forward: 5'-GGC CCT TCC TCG CTT CAT CTC-3' \\
\hline & Reverse: 5'-GGT CCT TGG GCC TTC CTG GTA T-3' \\
\hline \multirow{2}{*}{ Bax } & Forward: 5'-AAG CTG AGC GAG TGT CTC CGG CG-3' \\
\hline & Reverse: 5'-CAG ATG CCG GTT CAG GTA CTC AGT C-3' \\
\hline \multirow{2}{*}{ Bcl-2 } & Forward: 5'-CTC GTC GCT ACC GTC GTG ACT TGG-3' \\
\hline & Reverse: 5'-CAG ATG CCG GTT CAG GTA CTC AGT C-3' \\
\hline \multirow{2}{*}{ Bcl-xL } & Forward: 5'-CCC AGA AAG GAT ACA GCT GG-3' \\
\hline & Reverse: 5'-GCG ATC CGA CTC ACC AAT AC-3' \\
\hline \multirow{2}{*}{ XIAP } & Forward: 5'-CCG TGC GGT TGC TTT AGT TGT C-3' \\
\hline & Reverse: 5'-ATG GCA GGG TTC CTC GGG TAT-3' \\
\hline \multirow{2}{*}{ cIAP-1 } & Forward: 5'-TGAGCATGCAGACACATGC-3' \\
\hline & Reverse: 5'-TGACGGATGAACTCCTGTCC-3' \\
\hline \multirow{2}{*}{ cIAP-2 } & Forward: 5'-AATGGAAGATAGCACGAT-3' \\
\hline & Reverse: 5'-AGAAAGGCTGGAGTAAGA-3' \\
\hline \multirow{2}{*}{ Survivin } & Forward: 5'-CTT TCT CAA GGC CCA CCG CAT CT-3' \\
\hline & Reverse: 5'-GCA CTT TCT CCG CAG TTT CCT C-3' \\
\hline \multirow{2}{*}{ Fas } & Forward: 5'-GAA ATG AAA TCC AAA GCT-3' \\
\hline & Reverse: 5'-TAA TTT AGA GGC AAA GTG GC-3' \\
\hline \multirow{2}{*}{ FasL } & Forward: 5'-GGA TTG GGC CTG GGG ATG TTT CA-3' \\
\hline & Reverse: 5'-TTG TGG CTC AGG GGC AGG TTG TTG-3' \\
\hline \multirow{2}{*}{ TRAIL } & Forward: 5'-GGA ACC CAA GGT GGG TAG AT-3' \\
\hline & Reverse: 5'-TCT CAC CAC ACT GCA ACC TC-3' \\
\hline \multirow{2}{*}{ DR4 } & Forward: 5'-AAG TCC CTG CAC CAC GAC-3' \\
\hline & Reverse: 5'-CCA CAA CCT GAG CCG ATG-3' \\
\hline \multirow{2}{*}{ DR5 } & Forward: 5'-TGA GAT AAA GGT GGC TAA A -3' \\
\hline & Reverse: 5'-AAA GGT AAA CCA GGG AAG -3' \\
\hline \multirow{2}{*}{$\mathrm{NF}-\kappa \mathrm{B}$} & Forward: 5'-CAC TTA TGG ACA ACT ATG AGG TCT CTG G-3' \\
\hline & Reverse: 5'-CTG TCT TGT GGA CAA CGC AGT GGA ATT TTA GG-3' \\
\hline \multirow{2}{*}{ IкB- $\alpha$} & Forward: 5'-GCT GAA GAA GGA GCG GCT ACT-3' \\
\hline & Reverse: 5'-TCG TAC TCC TCG TCT TTC ATG GA-3' \\
\hline \multirow{2}{*}{ GAPDH } & Forward: 5'-CGG AGT CAA CGG ATT TGG TC-3' \\
\hline & Reverse: 5'-AGC CTT CTC CAT GGT CGT GA-3' \\
\hline
\end{tabular}

\subsection{Western Blot Assay}

Total protein was obtained from the HSC-3 cells using Radio-Immunoprecipitation assay buffer as previously described [12]. The protein concentrations were determined using a Bio-Rad protein assay kit. The nitrocellulose membranes (Schleicher and Schuell; Keene, NH, USA) were then subjected to immunoblot analysis and the proteins were visualized using an enhanced chemiluminescence (ECL) 
method (GE Healthcare). Fifty micrograms of protein from treated cells was loaded onto the gels. The cell lysates were separated using 12\% SDS-PAGE, transferred onto a polyvinylidene fluoride membrane (GE Healthcare), blocked with 5\% skim milk and then hybridized with primary antibodies (diluted 1:1000). The antibodies against caspase-3, caspase-8, caspase-9, Bax, Bcl-2, Bcl-xL, XIAP, cIAP-1, cIAP-2, survivin, Fas, FasL, TRAIL, DR4, DR5, NF- $\kappa$ B and I $\mathrm{B}-\alpha$ were obtained from Santa Cruz Biotechnology (Santa Cruz, CA, USA). The membranes were then incubated with the HRP-conjugated secondary antibodies (Santa Cruz Biotechnology) for $1 \mathrm{~h}$ at room temperature. The blots were washed 3 times with PBS-T and then developed using an ECL reagent (Amersham Life Science; Arlington Heights, IL, USA).

\subsection{Statistical Analysis}

Data are presented as mean \pm standard deviation (SD). Differences between the mean values for individual groups were assessed with one-way analysis of variance (ANOVA) with Student-Neumann-Keuls post-hoc test, and the data were tested for a two-sided statistical testing. $p<0.01$ and $p<0.05$ were considered to indicate a statistically significant difference. SPSS software 19.0 (IBM Software; New York, NY, USA) was used for statistical analyses.

\section{Results}

\subsection{Inhibitory Effects of Ursodeoxycholic Acid (UDCA), Chenodeoxycholic Acid (CDCA) and} Deoxycholic Acid (DCA) on Cell Growth

In vitro growth effects of UDCA, CDCA and DCA on oral cancer and normal cells were evaluated using the MTT assay. At concentrations ranging from 0 to $500 \mu \mathrm{g} / \mathrm{mL}$ of UDCA, CDCA and DCA, human oral squamous carcinoma HSC-3 cells and TCA8113 cell viabilities were decreased by UDCA, CDCA and DCA in a concentration-dependent manner. At a concentration of $500 \mu \mathrm{g} / \mathrm{mL}$, inhibition of the HSC-3 cells treated with UDCA reached $100 \%$ and at a concentration of $400 \mu \mathrm{g} / \mathrm{mL}$, inhibition of the HSC-3 cells treated with CDCA and DCA reached 100\% (Figure 1A). UDCA, CDCA and DCA also showed similar inhibitory effects in HSC-3 cells and TCA8113 cells at 0 to $500 \mu \mathrm{g} / \mathrm{mL}$ (Figure 1B). HOK normal oral epithelial cells were also evaluated, and there was no response in HOK normal oral cells treated with UDCA at concentrations of $0-400 \mu \mathrm{g} / \mathrm{mL}$, but inhibition started once the concentration of UDCA exceeded $400 \mu \mathrm{g} / \mathrm{mL}$ (Figure 1C). HOK normal cell growth was also decreased by CDCA and DCA in a concentration-dependent manner. The inhibitory rates were higher than UDCA treatment from 0-500 $\mu \mathrm{g} / \mathrm{mL}$. At 0-400 $\mu \mathrm{g} / \mathrm{mL}$, UDCA had no toxic effect in normal oral cells, and only showed a lethal effect in oral cancer cells. This might be an apoptotic effect. CDCA and DCA showed toxic effects in normal cells at concentrations from 0 to $400 \mu \mathrm{g} / \mathrm{mL}$. From these results, UDCA as a bile acid, it was different from CDCA and DCA. Consequently, concentrations of 100, 200 and $400 \mu \mathrm{g} / \mathrm{mL}$ were selected for subsequent experiments. 
(A)

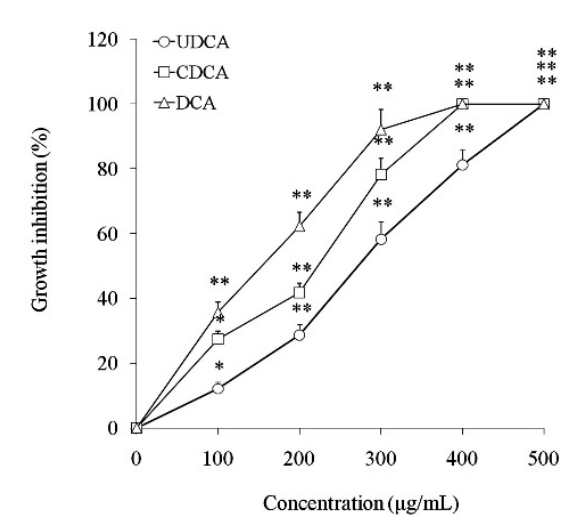

(B)

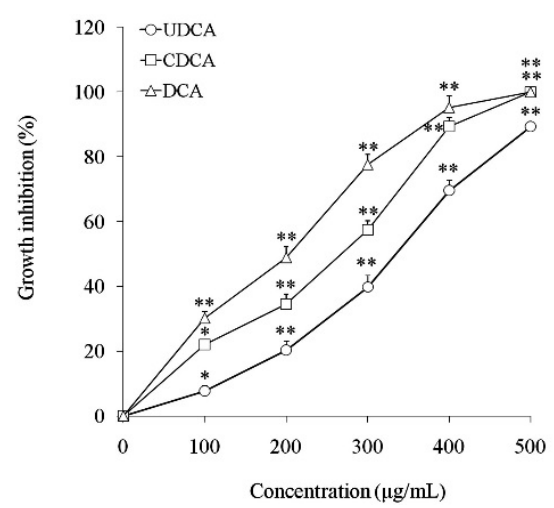

(C)

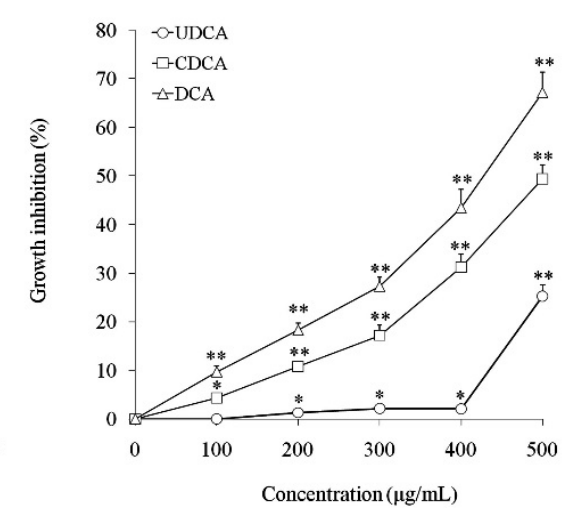

Figure 1. Growth inhibitory effects of ursodeoxycholic acid (UDCA), chenodeoxycholic acid (CDCA) and deoxycholic acid (DCA) in human oral squamous carcinoma HSC-3 cells (A), TCA8113 human tongue carcinoma cells (B), and HOK normal oral epithelial cells (C).

* Mean values are significantly different from $0 \mu \mathrm{g} / \mathrm{mL}$ sample treatment $(p<0.05)$ and ** mean values are significantly different from $0 \mu \mathrm{g} / \mathrm{mL}$ sample treatment $(p<0.01)$.

\subsection{Induction of Apoptosis by UDCA}

To determine a possible mechanism underlying the growth inhibitory activity of UDCA in HSC-3 oral cancer cells, the induction of apoptosis was explored. The extent of chromatin condensation was analyzed by fluorescence microscopy of cells stained with the DNA-binding fluorescent dye DAPI and flow cytometric analysis. While the untreated HSC-3 cancer cells presented nuclei with homogeneous chromatin distribution, treatment with UDCA induced chromatin condensation and nuclear fragmentation, which suggests initiation of apoptosis. At a high concentration of $400 \mu \mathrm{g} / \mathrm{mL}$, the UDCA treated HSC-3 cells underwent apoptosis and only a small amount of HSC-3 cancer cells were not affected. (Figure 2A). Chromatin condensation and the formation of apoptotic bodies, two hallmarks of apoptosis, were observed in cells cultured with 200 and $400 \mu \mathrm{g} / \mathrm{mL}$ of UDCA. In contrast, the level of chromatin condensation was low in the untreated control cells. Flow cytometric analyses revealed that treatment with UDCA promoted apoptosis of the HSC-3 cells compared with incubation with control cells. This conclusion is based on the significant accumulation of 100, 200 and $400 \mu \mathrm{g} / \mathrm{mL}$ treated cancer cells with sub-G1 DNA content at $10.6 \%, 22.4 \%$ and $41.3 \%$ compared to the control cells (2.7\%) (Figure 2B). 


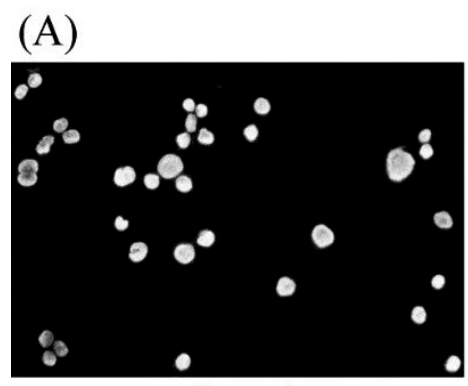

Control

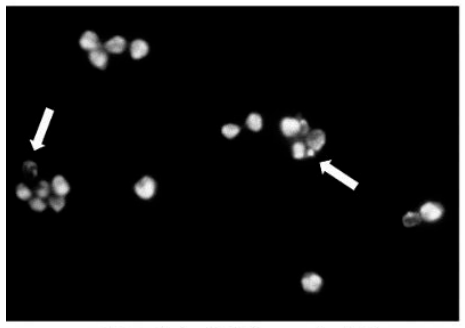

$\operatorname{UDCA}(200 \mu \mathrm{g} / \mathrm{mL})$

(B)
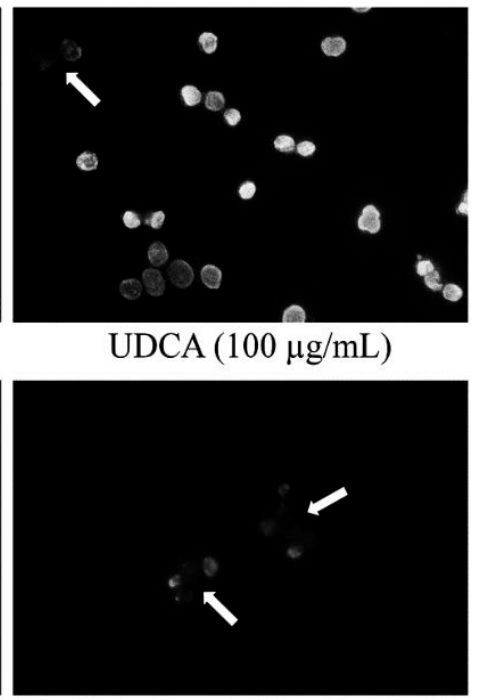

$\operatorname{UDCA}(400 \mu \mathrm{g} / \mathrm{mL})$

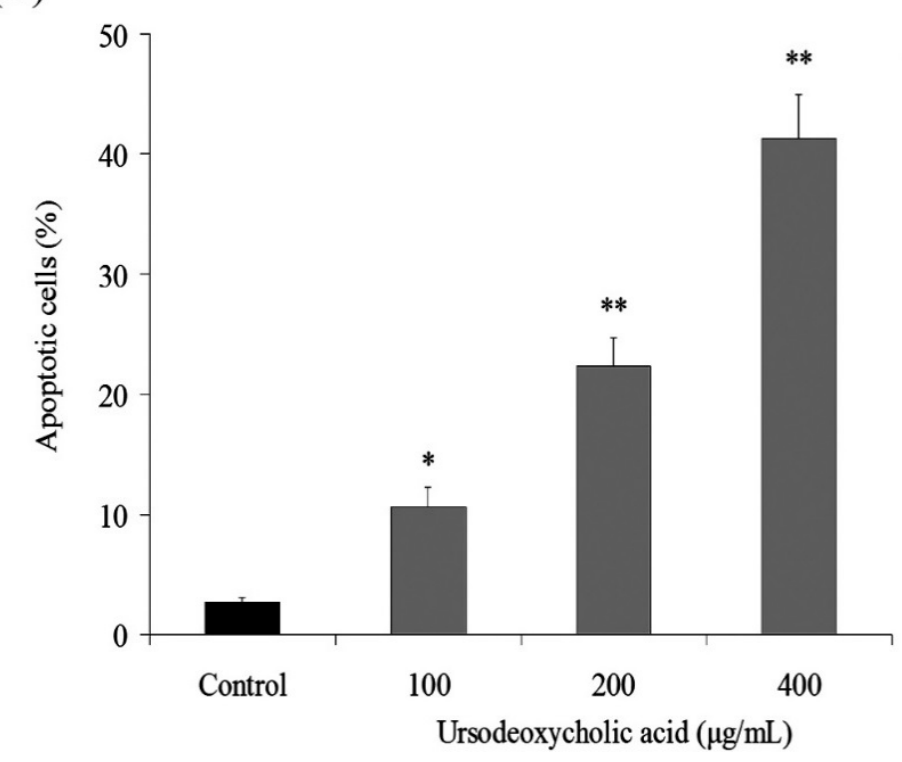

Figure 2. Exposure of human oral squamous carcinoma HSC-3 cells to ursodeoxycholic acid (UDCA) induced apoptosis. (A) Appearance of apoptotic bodies in HSC-3 cells treated with UDCA for $48 \mathrm{~h}(200 \times)$; and (B) treatment with UDCA for $48 \mathrm{~h}$ increased the number of apoptotic cells as measured by flow cytometry. The profile represents an increased sub-G1 population (apoptotic cells). * Mean values are significantly different from control $(p<0.05)$ and $* *$ mean values are significantly different from control $(p<0.01)$.

\subsection{Gene Expression of Caspase Family}

The mRNA expression of caspase- 3 , caspase- 8 and caspase- 9 in HSC-3 oral cancer cells were analyzed by RT-PCR and Western blot assays. After UDCA treatment, the mRNA and protein expression of caspase- 3 , caspase- 8 and caspase- 9 were increased compare to the control cells, and these changes were increased in a concentration-dependent manner (Figure 3). 


\section{(A)}
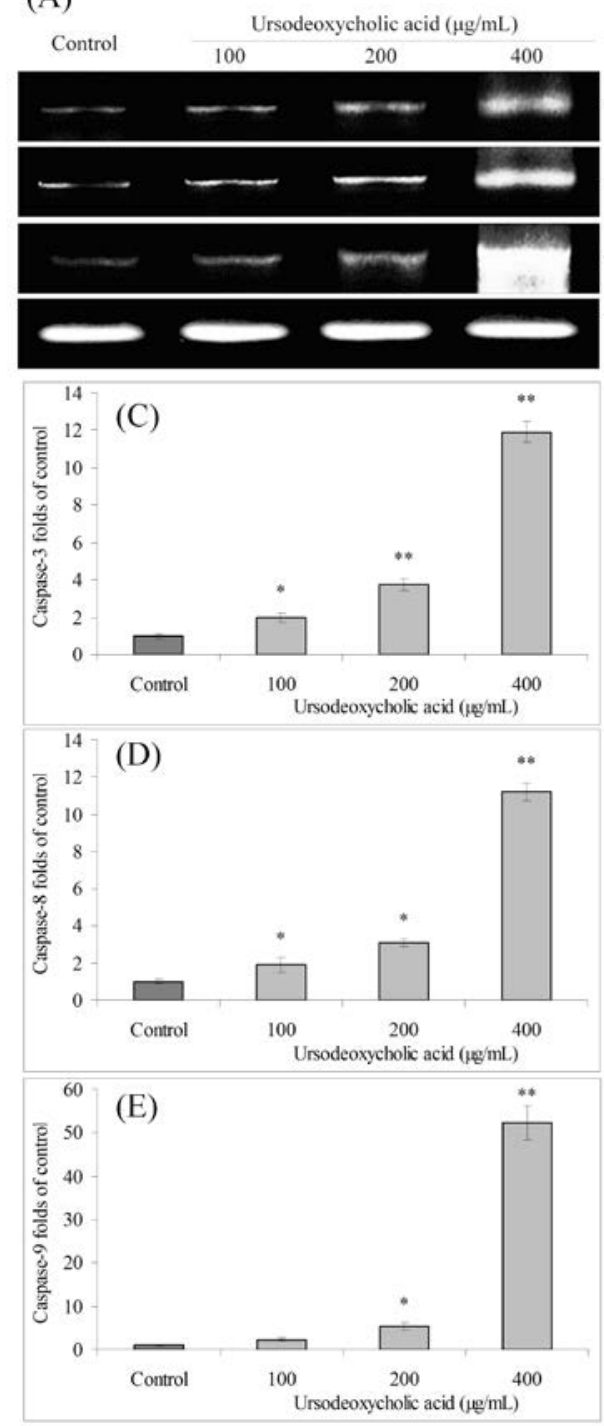

(B)

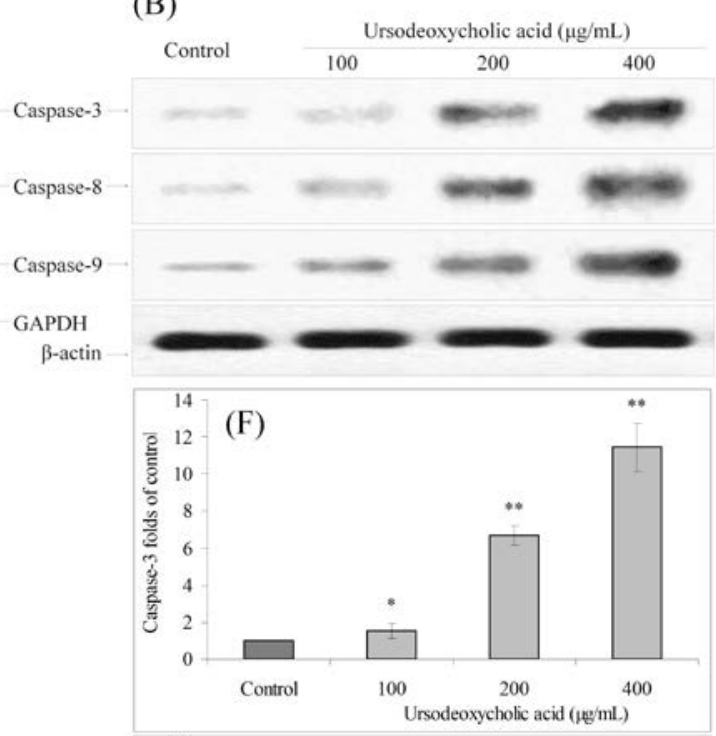

(G)

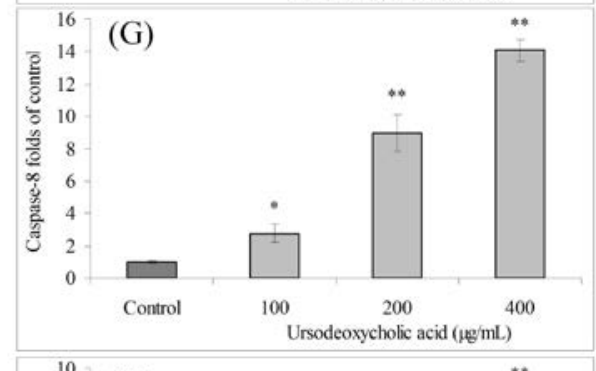

$(\mathrm{H})$

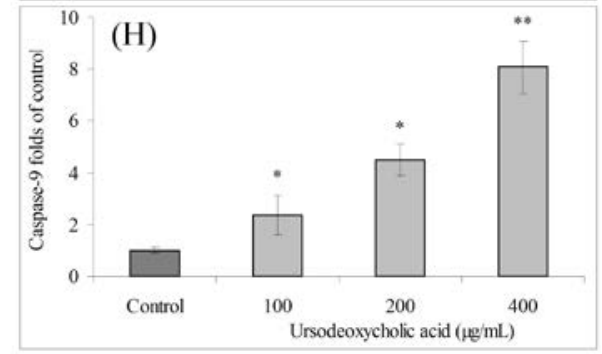

Figure 3. Effects of ursodeoxycholic acid (UDCA) on the mRNA (A) and protein (B) expression of capase-3, capase- 8 and capase- 9 in human oral squamous carcinoma HSC-3 cells. Fold-ratio: gene expression/GAPDH $(\beta$-actin) $\times$ control numerical value (control fold ratio: 1); (C), caspase-3 mRNA expression fold over control; (D), caspase-8 mRNA expression fold over control; (E), caspase-9 mRNA expression fold over control; (F), caspase-3 protein expression fold over control; (G), caspase-8 protein expression fold over control; and $(\mathbf{H})$, caspase-9 protein expression fold over control. * Mean values are significantly different from control $(p<0.05)$ and $* *$ mean values are significantly different from control $(p<0.01)$.

\subsection{Gene Expression of Bcl-2 Family}

UDCA also significantly changed the mRNA and protein expression of Bax, Bcl-2 and Bcl-xL in HSC-3 cancer cells (Figure 4). At the concentration of $400 \mu \mathrm{g} / \mathrm{mL}$, UDCA treated cancer cells showed the highest Bax expression, and lowest Bcl-2, Bcl-xL expressions. The Bax expressions of 100 and $200 \mu \mathrm{g} / \mathrm{mL}$ UDCA treated cancer cells were also higher than control cells, and Bcl-2, Bcl-xL expressions were lower than those of control cells. 
(A)
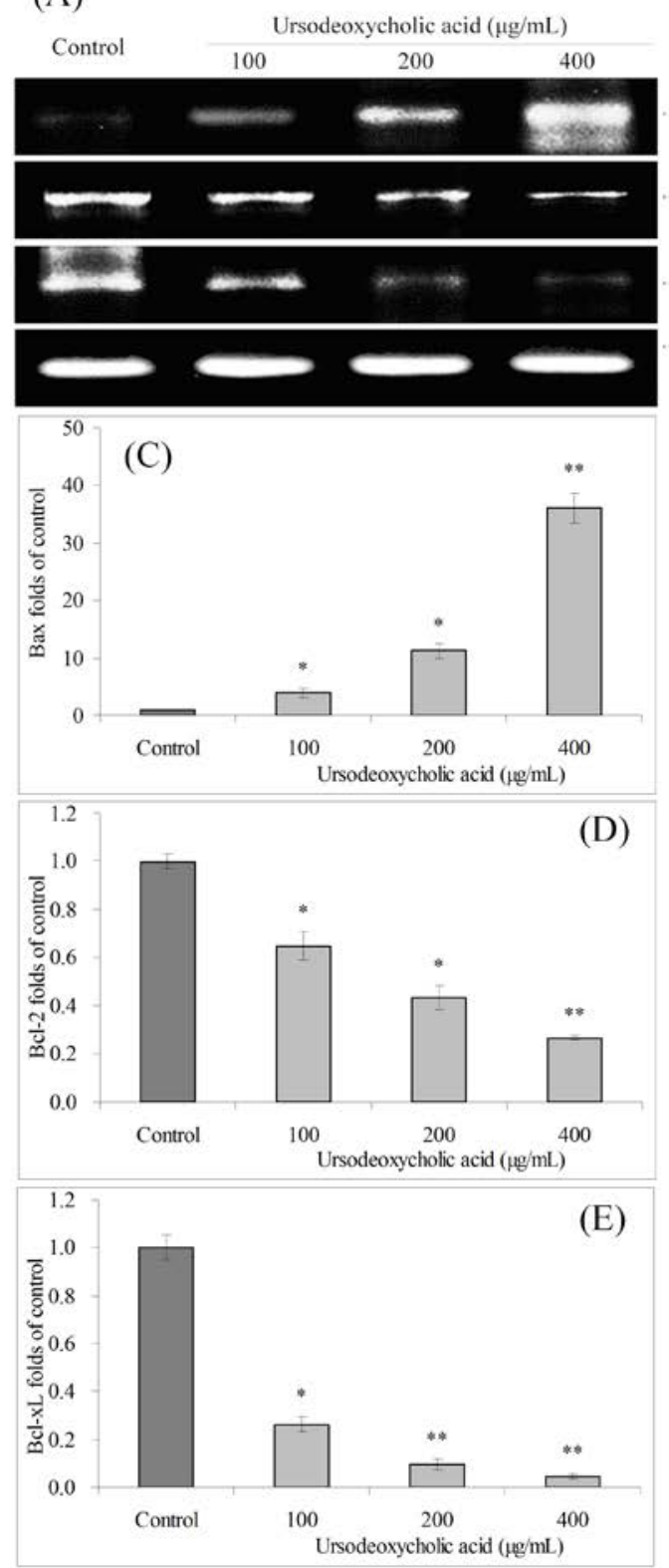

(B)
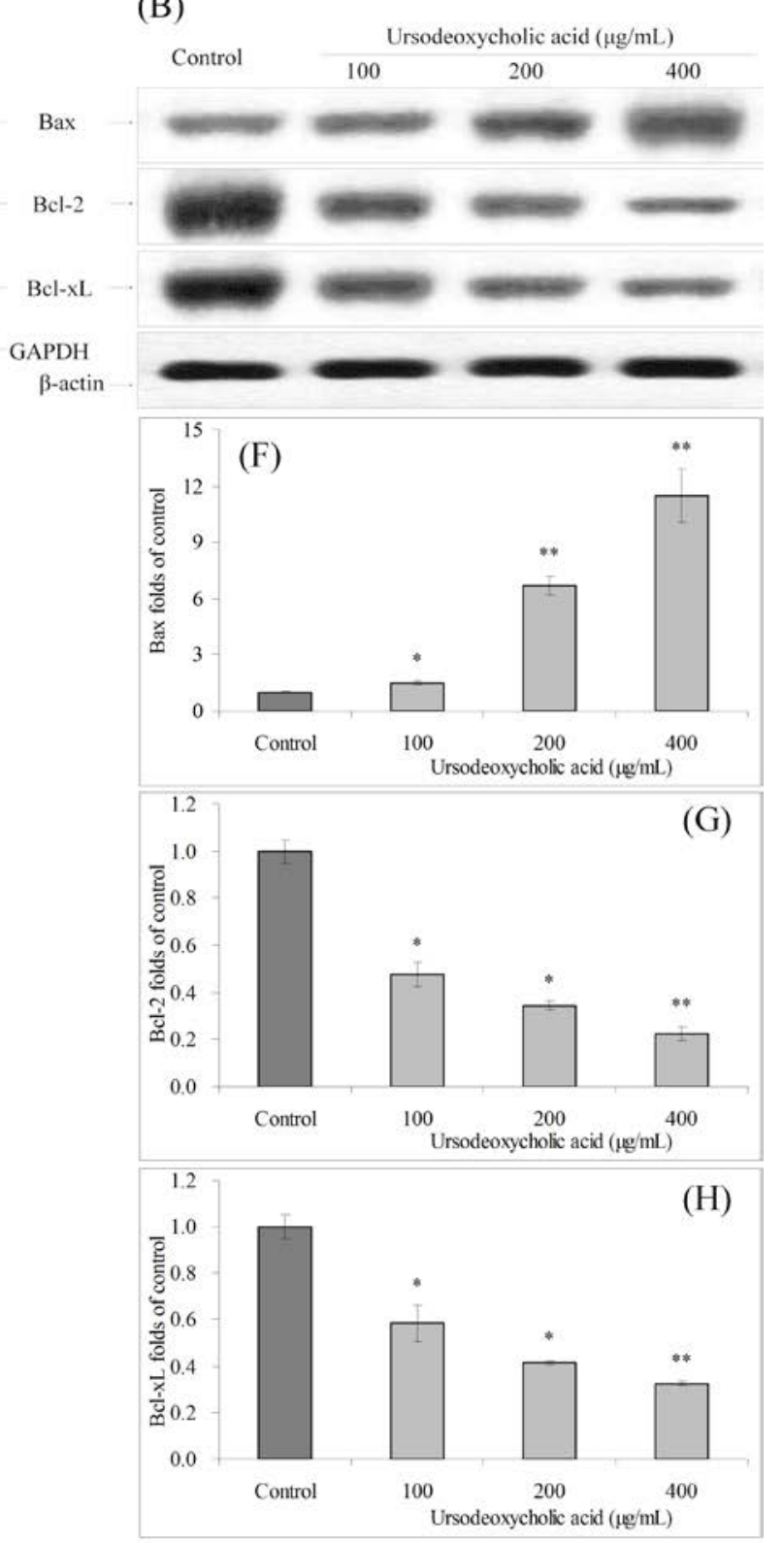

Figure 4. Effects of ursodeoxycholic acid (UDCA) on the mRNA (A) and protein (B) expression of Bax, Bcl-2 and Bcl-xL in human oral squamous carcinoma HSC-3 cells. Fold-ratio: gene expression/GAPDH $(\beta$-actin) $\times$ control numerical value (control fold ratio: 1); (C), Bax mRNA expression fold over control; (D), Bcl-2 mRNA expression fold over control; (E), Bcl-xL mRNA expression fold over control; (F), Bax protein expression fold over control; (G), Bcl-2 protein expression fold over control; and (H), Bcl-xL protein expression fold over control. * Mean values are significantly different from control $(p<0.05)$ and $* *$ mean values are significantly different from control $(p<0.01)$.

\subsection{Gene Expression of XIAP, cIAP-1, cIAP-2 and Survivin}

The mRNA and protein expressions of XIAP, cIAP-1, cIAP-2 and survivin were reduced in UDCA treated HSC-3 cancer cells (Figure 5). The 100, 200 and $400 \mu \mathrm{g} / \mathrm{mL}$ UDCA treated cells had lower XIAP, cIAP-1, cIAP-2 and survivin expression than control HSC-3 cells. 
(A)
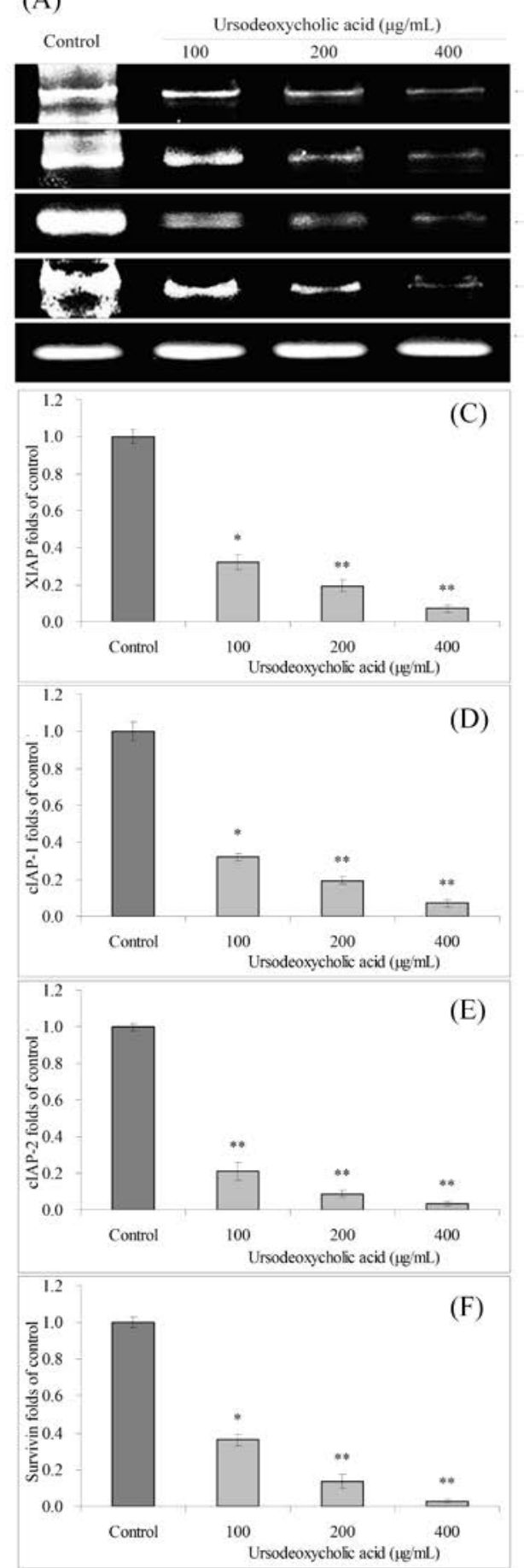

(B)

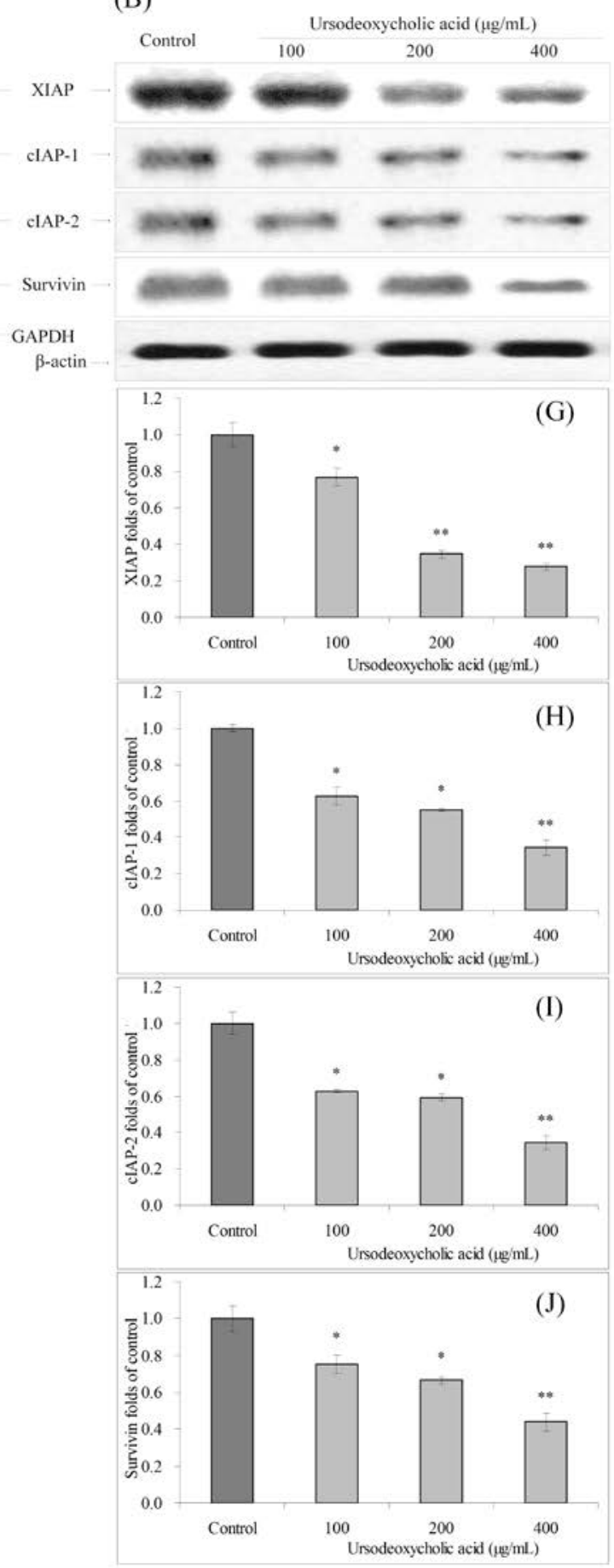

Figure 5. Effects of ursodeoxycholic acid (UDCA) on the mRNA (A) and protein (B) expression of XIAP, cIAP-1, cIAP-2 and survivin in human oral squamous carcinoma HSC-3 cells. Fold-ratio: gene expression/GAPDH ( $\beta$-actin) $\times$ control numerical value (control fold ratio: 1); (C), XIAP mRNA expression folds of control; (D), cIAP-1 mRNA expression folds of control; (E), cIAP-2 mRNA expression folds of control; (F), survivin mRNA expression folds of control; (G), XIAP protein expression folds of control; (H), cIAP-1 protein expression folds of control; (I), cIAP-2 protein expression folds of control; and (J), survivin protein expression folds of control. * Mean values are significantly different from control $(p<0.05)$ and $* *$ mean values are significantly different from control $(p<0.01)$. 


\subsection{Gene Expression of Fas and FasL}

Fas and FasL mRNA and protein expressions were increased, and the Fas/FasL ratio was also increased with UDCA treatment. Fas expression increased after UDCA treatment, and FasL expression increased slightly (Figure 6). The Fas/FasL ratio with $400 \mu \mathrm{g} / \mathrm{mL}$ UDCA treated cancer cells was much higher than control cells.

(A)
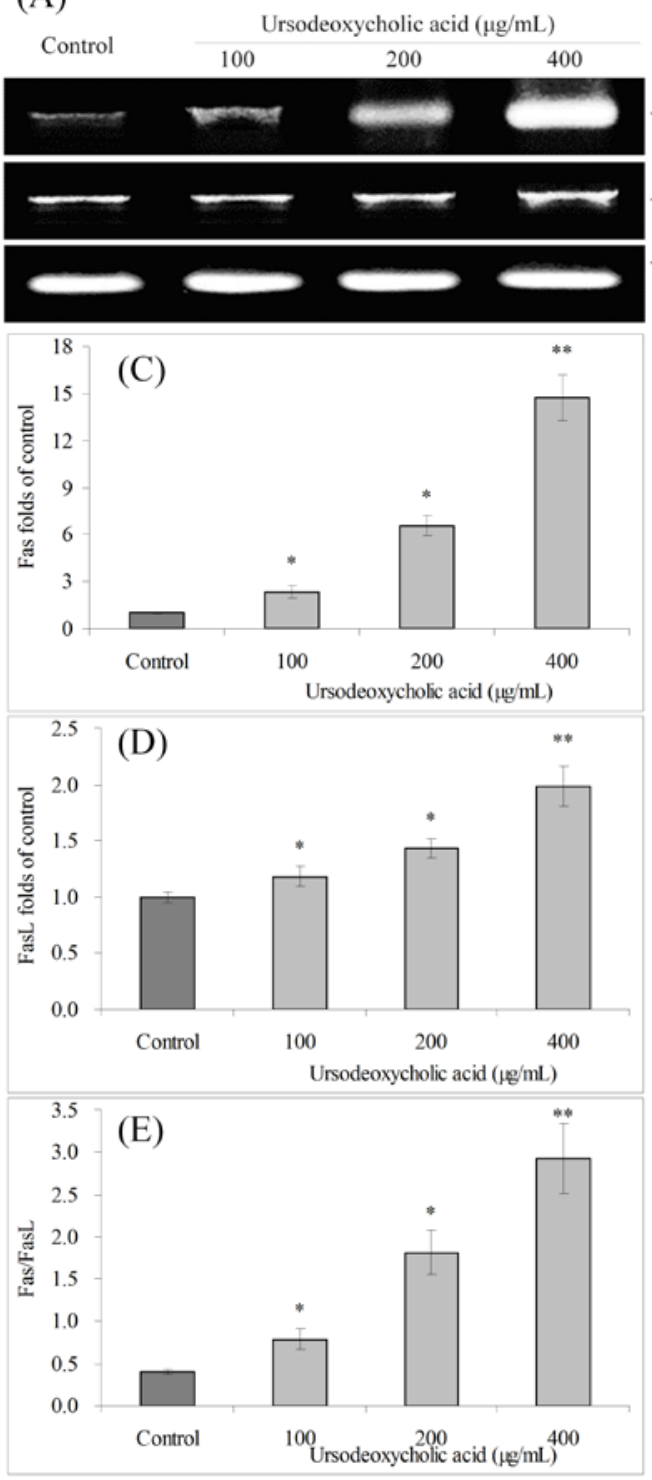

(B)
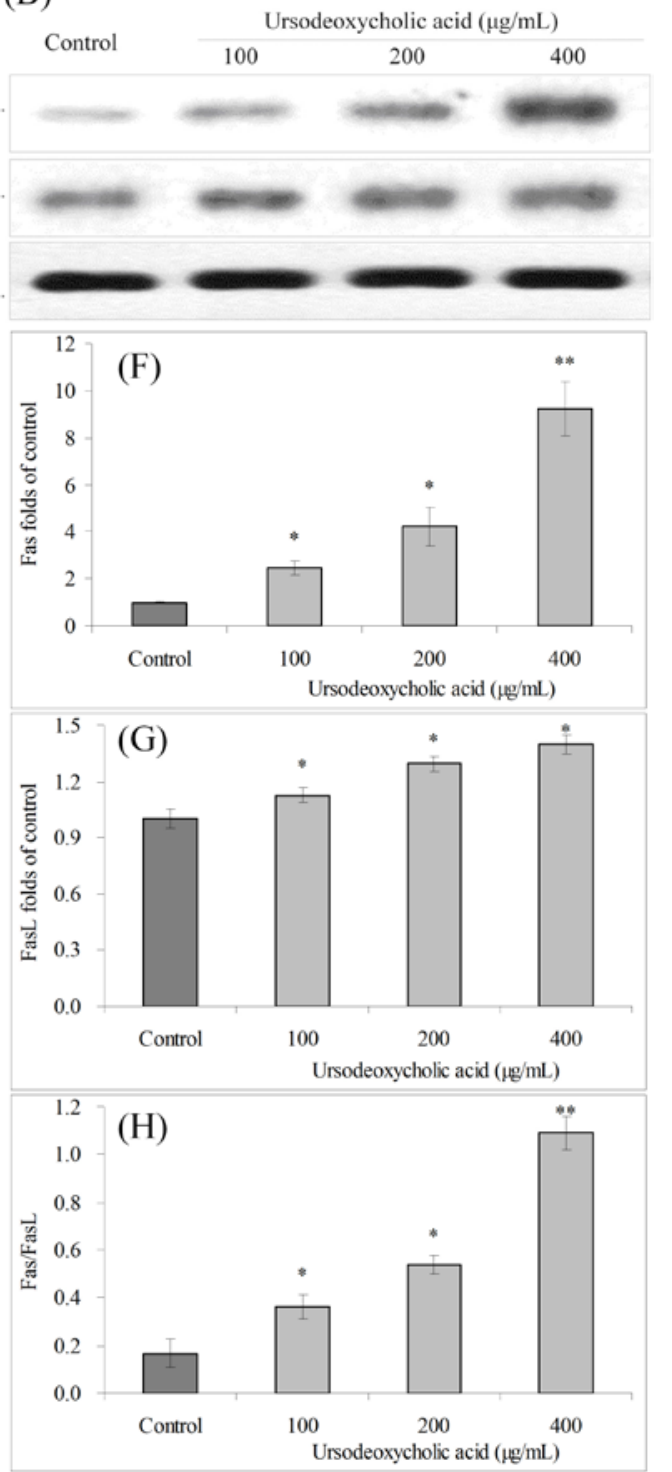

Figure 6. Effects of ursodeoxycholic acid (UDCA) on the mRNA (A) and protein (B) expression of Fas and FasL in human oral squamous carcinoma HSC-3 cells. Fold-ratio: gene expression/GAPDH ( $\beta$-actin) $\times$ control numerical value (control fold ratio: 1$)$; (C), Fas mRNA expression folds of control; (D), FasL mRNA expression folds of control; (E), Fas/FasL mRNA expression proportion; (F), Fas protein expression folds of control; (G), FasL protein expression folds of control; and $(\mathbf{H})$, Fas/FasL protein expression proportion. * Mean values are significantly different from control $(p<0.05)$ and $* *$ mean values are significantly different from control $(p<0.01)$. 


\subsection{Gene Expression of TRAIL, DR4 and DR5}

UDCA also significantly increased the mRNA and protein expression of TRAIL, DR4 and DR5 compared to control cells (Figure 7). UDCA increased the expression of DR4 and DR5, with the mRNA expression with $400 \mu \mathrm{g} / \mathrm{mL}$ UDCA treatment were 19.46 and 8.34 times greater, and protein expression were 9.31 and 1.82 times greater than control cells. TRAIL mRNA and protein levels with $400 \mu \mathrm{g} / \mathrm{mL}$ UDCA treatment were only 2.42 and 5.30 times greater than control cells.

(A)
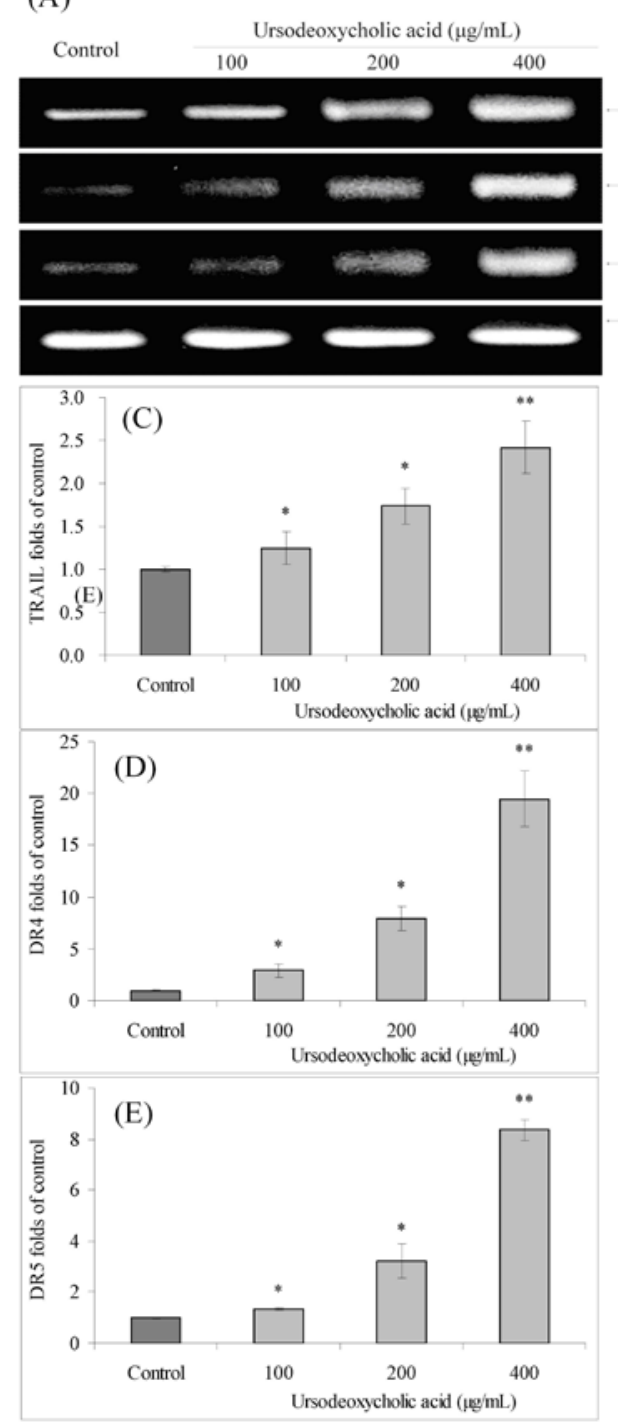

(B)
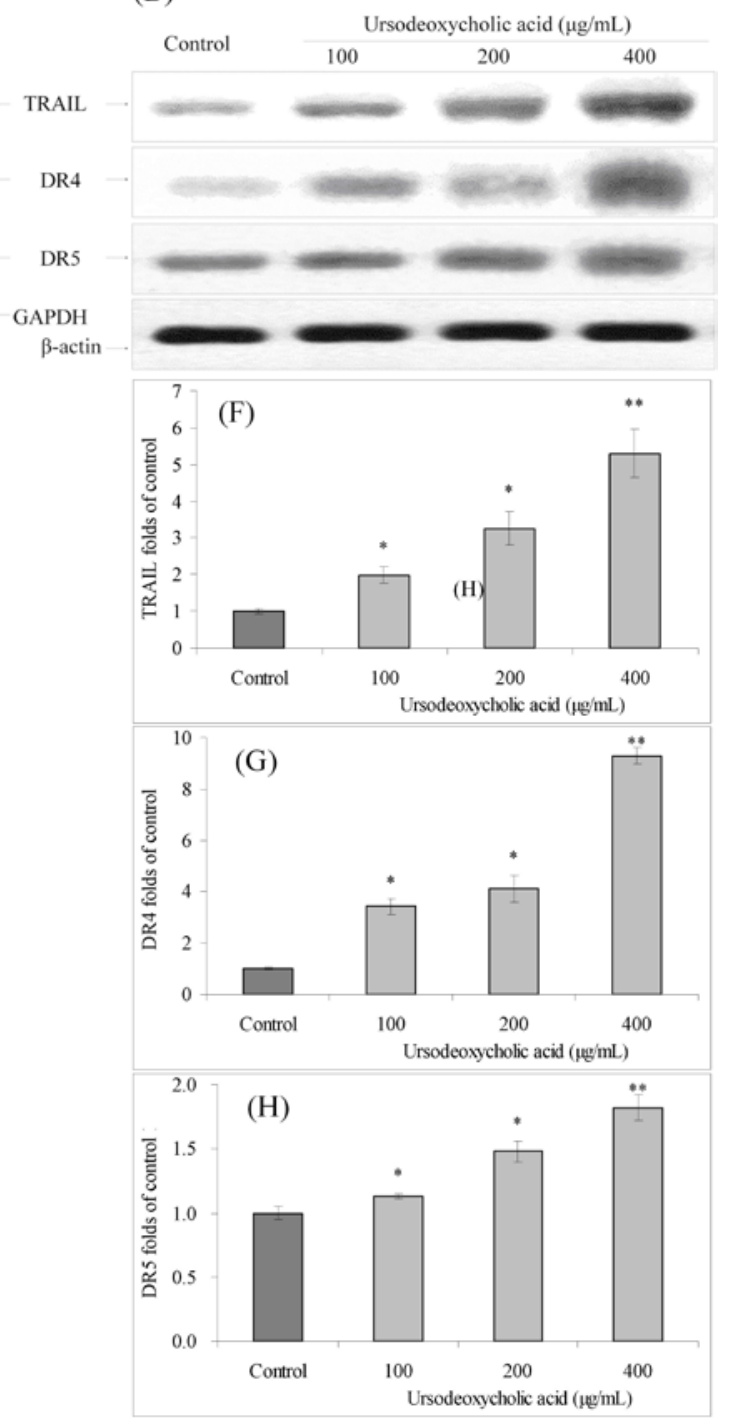

Figure 7. Effects of ursodeoxycholic acid (UDCA) on the mRNA (A) and protein (B) expression of TRAIL, DR4 and DR5 in human oral squamous carcinoma HSC-3 cells. Fold-ratio: gene expression/GAPDH ( $\beta$-actin) $\times$ control numerical value (control fold ratio: 1 ); (C), TRAIL mRNA expression folds of control; (D), DR4 mRNA expression folds of control; (E), DR5 mRNA expression folds of control; (F), TRAIL protein expression folds of control; (G), DR4 protein expression folds of control; and (H), DR5 protein expression folds of control. * Mean values are significantly different from control $(p<0.05)$ and ** mean values are significantly different from control $(p<0.01)$. 


\subsection{Gene Expression of $N F-\kappa B$ and $I \kappa B-\alpha$}

UDCA could decrease the mRNA and protein expression of NF- $\kappa \mathrm{B}$ and increase the expression of I $\mathrm{B}-\alpha$ compared to control cells (Figure 8).
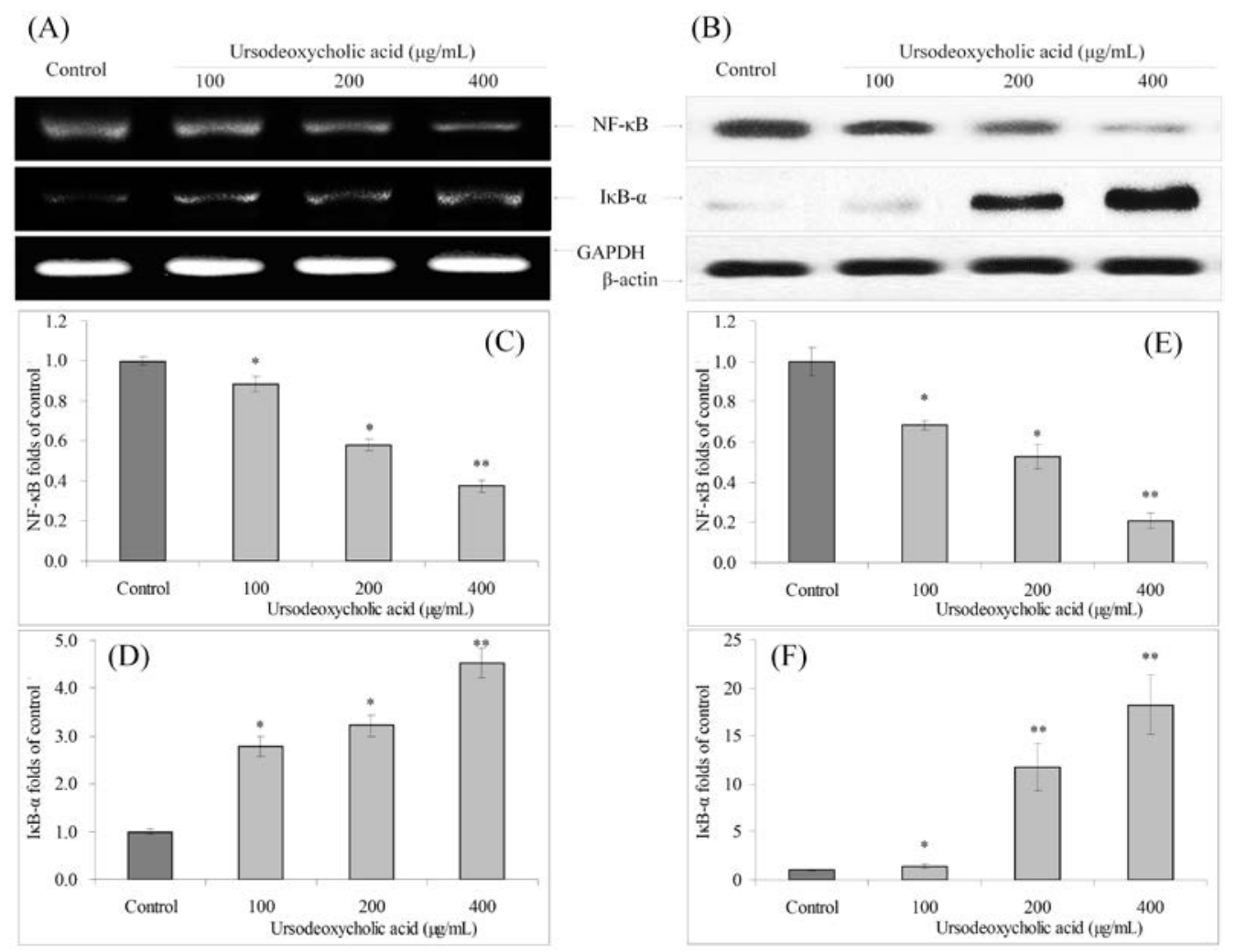

Figure 8. Effects of ursodeoxycholic acid (UDCA) on the mRNA (A) and protein (B)

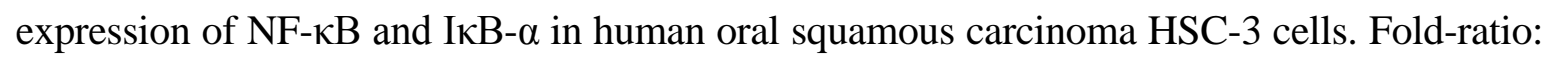
gene expression/GAPDH ( $\beta$-actin) $\times$ control numerical value (control fold ratio: 1 );

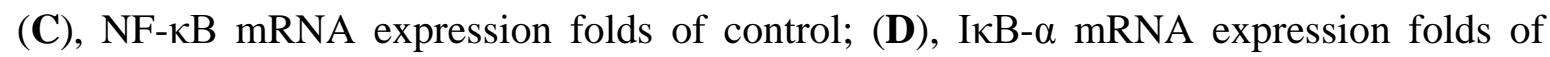

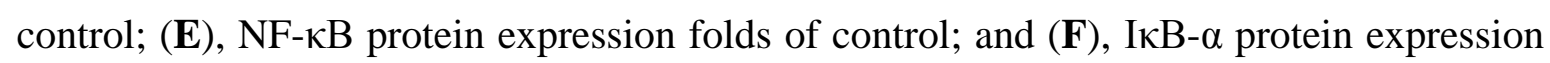
folds of control. * Mean values are significantly different from control $(p<0.05)$ and ** mean values are significantly different from control $(p<0.01)$.

\section{Discussion}

By evaluating the effect of UDCA on cancer and normal cells, it was seen that UDCA could significantly inhibit the growth of oral cancer cells in vitro and promote their death at and below $400 \mu \mathrm{g} / \mathrm{mL}$, but it showed no obvious influence on normal oral cells at these concentrations. As a result, in this range of concentrations, UDCA was safe to normal oral cells and only affects cancer cells. UDCA showed inhibitory effects both in HSC-3 and TCA8813 cancer cells. The HSC-3 cell line was often used for oral science research [13-15] and was chosen for further experiments in this study. By using flow cytometry to detect cellular DNA content, it could be seen that the inhibitory effect of UDCA on cancer cell growth was in part due to promoting cancer cells into the sub-G1 phase and generating more 
apoptotic cells. Furthermore, evaluating the cells morphologically, UDCA could induce more cancer cell apoptosis visualized by DAPI staining.

GAPDH gene is stably and constitutively expressed at high expression levels in cancer cells and is used as a housekeeping gene. [16]. $\beta$-actin has relatively high and constant expression in the total protein of cancer cells. Therefore, $\beta$-actin has been widely employed in Western blotting as a loading control [17]. In this study, GAPDH and $\beta$-actin were also used as controls for RT-PCR and Western blot assays, respectively. The most important link in the mechanism of apoptosis is the activation of caspases. Caspases are proteases that participate in the control of cell growth and apoptosis [18]. Caspase-8 and caspase- 9 are caspases upstream to the apoptosis signal transduction process, while caspase- 3 is downstream, all of which are effector molecules of cell apoptosis [19]. Caspase-9 is an apoptosis effector molecule in the mitochondrial channel and starts the programmed cell death after activation. Subsequently, caspase-3 is activated, which amplifies and executes apoptotic signals and leads to apoptosis [20]. Studies have shown that with exogenous stimulation, the expression of caspase-3, caspase-8 and caspase-9 in in vitro cultured cancer cells were increased [11]. In a previous study, UDCA could also increase caspase-3, caspase- 8 and caspase- 9 activities to induce apoptosis in HepG2 hepatocellular carcinoma cells [21]. UDCA induced apoptosis through caspase-3 and also increased caspase-3 by decreasing Bcl-2 [22]. In this study, UDCA increased the mRNA and protein expressions of caspase-3, caspase-8 and caspase-9 in HSC-3 cells, signifying that UDCA treatment had anticancer effects through induction of caspases.

In apoptosis, the Bcl-2 family of proteins plays an important role because some of its members can promote apoptosis, such as Bax, while some members can prevent apoptosis, such as Bcl-2 and Bcl-xL [23]. Bcl-2 can prevent the release of cytochrome c (Cyt-c) from the mitochondria to the cytoplasm, thus inhibiting apoptosis. Bcl-2 is the most important member in the Bcl-2 family of proteins and regarded as an inhibitory effector of cell apoptosis [24]. In apoptosis signaling, Bcl-2 acts upstream of the activation of caspase-3 and inhibits its activation. Recent studies further showed that Bcl-2 not only acts upstream of caspase-3, but is also a direct substrate of caspase-3. After cleavage by caspase-3, the function of Bcl-2 completely changes from inhibition of apoptosis to promotion [25]. The Bcl-2 family of proteins is related to the caspase family of proteins in cancer cell apoptosis and treatment with UDCA increased Bax expression and reduced $\mathrm{Bcl}-2$, Bcl-xL expression, thus possibly affecting the expressions of caspase-3, caspase-8, and caspase- 9 .

XIAP, the main member in the IAP family of proteins, is the strongest apoptosis inhibiting factor of the IAP family, and can directly inhibit caspases and regulate cell apoptosis in various ways. XIAP genes are expressed in most tumor cell lines, and its expression is closely related to tumor progression, recurrence, prognosis, and drug resistance to chemotherapy [26]. The main function of cIAP-1 is to mediate tumor necrosis factor receptor family for inhibition of apoptosis and decreasing apoptosis through direct interaction with caspase-3 [27]. Similarly, cIAP-2 is another kind of effective inhibitor of apoptosis by blocking the activity of caspase- 9 induced by cytochrome c [28]. UDCA could increase the expression of caspases with XIAP, cIAP-1, and cIAP-2 decreased expression.

Survivin directly acts on caspases by inhibiting their activities and indirectly inhibiting caspases through p21. A combination of survivin and cell cycle regulation factor CDK4 can cause activation of CDK2/Cyclin-E and phosphorylation of ribosomes (Rb) [29]. Rb phosphorylation starts the cell cycle and speeds up transition between the G1/S phase, which causes p21 release from survivin-CDK4 
complexes, which interacts with mitochondria pro-caspase-3, inhibiting the activity of caspase-3 and preventing release of Cyt-c from the mitochondria and ultimately inhibiting cell apoptosis [30]. UDCA could also reduce survivin expression, leading to increased caspases.

Fas is a death receptor and FasL is a product of $\mathrm{T}$ lymphocytes. Interaction between Fas and FasL can induce apoptosis [31]. Fas/FasL mediated apoptosis is the main pathway of cell apoptosis, transmitting apoptotic signals to caspases, activating a series of caspases to participate in apoptosis, and achieving self-regulation of caspases through cycle amplification and heterologous oligomerization [32]. Fas/FasL of HSC-3 oral cancer cells was changed with UDCA treatment.

After combination of death receptors DR4, DR5 and TRAIL, oligomerization of death receptors occur and increases FADD molecules (Fas-associated death domain; also known as Mort1), which contain a DD (death domain) at the end of the $C$-terminus and a DED (death effector domain) at the $N$-terminus [33]. FADD can combine with receptors through the interaction between two DDs and increase the precursor of caspase-8, which is the initiator of apoptosis (pro-caspase-8), via the interaction between DED, and finally form the death signal complex DISC (death-inducing signaling complex). Within the DISC, the precursor of caspase-8 is activated to form caspase-8, thus causing apoptosis [34]. UDCA could increase DR4, DR5 and TRAIL, and this effect could promote caspase activation and induce apoptosis.

Defects in NF- $\kappa$ B increased susceptibility to apoptosis leading to increased cancer cells death. $\mathrm{NF}-\kappa \mathrm{B}$ regulates anti-apoptotic genes, especially the caspase family (generally speaking caspase family of proteins is not anti-apoptotic) [35]. Caspases could activate the NF- $\kappa \mathrm{B}$ pathway independent of its activity as a pro-apoptotic protease. Death effector domains containing homologs of caspase-8 could similarly activate the NF- $\mathrm{BB}$ pathway. Dominant-negative mutants of the caspase-8 prodomain could block NF- $\kappa$ B induction by caspase-8 [36]. NF- $\kappa B$ is located in the cytosol complexed with the inhibitory

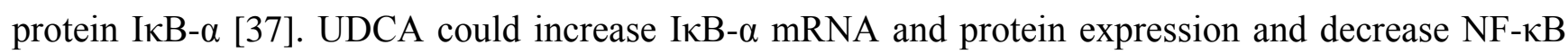
expression, aiding apoptosis.

\section{Conclusions}

As a monomeric material, UDCA has been introduced as treatment for various diseases, while the mechanism of the monomeric materials needs further research. By evaluating changes in gene and protein expression in cancer cells with UDCA treatment, we show that UDCA can be applied for the treatment of oral cancers. Preliminary in vitro experiments confirm that UDCA can induce cancer cell apoptosis by promoting caspase-3, caspase-8, caspase-9, Bax, Fas/FasL, TRAIL, DR4, DR5 and IкB- $\alpha$ gene expression in cancer cells, and reduce the expression of Bcl-2, Bcl-xL, XIAP, cIAP-1, cIAP-2, survivin and NF- $\kappa \mathrm{B}$.

\section{Acknowledgments}

This research was supported by Chongqing Medical Scientific and Technological Project (2011-1-060), China. 


\section{Author Contributions}

The work presented here was carried out in collaboration between all authors. Liang Pang and Lihua Qiu defined the research theme. Liang Pang, Xin Zhao, Weiwei Liu and Lihua Qiu designed methods and experiments, carried out the laboratory experiments, analyzed the data, interpreted the results and wrote the paper. Jiang Deng and Xiaotong Tan co-designed the dispersal and colonization experiments, and co-worked on associated data collection and their interpretation. All authors have contributed to, seen and approved the manuscript.

\section{Conflicts of Interest}

The authors declare no conflict of interest.

\section{References}

1. Chi, C.G. Synthetic and pharmacological research progress of primary chemical components in bear bile. Strait. Pharm. J. 2008, 20, 5-8.

2. Lee, S.H.; Cheon, G.J.; Kim, H.S.; Kim, Y.D.; Kim, S.G.; Kim, Y.S.; Jeong, S.W.; Jang, J.Y.; Kim, B.S. Comparison on the efficacy and safety of biphenyl dimethyl dicarboxylate and ursodeoxycholic acid in patients with abnormal alanine aminotransferase: Multicenter, double-blinded, randomized, active-controlled clinical trial. Korean J. Gastroenterol. 2014, 64, 31-39.

3. Chaturvedi, A.K.; Engels, E.A.; Anderson, W.F.; Gillison, M.L. Incidence trends for human papillomavirus-related and -unrelated oral squamous cell carcinomas in the United States. J. Clin. Oncol. 2008, 26, 612-619.

4. Michaud, D.S.; Izard, J.; Rubin, Z.; Johansson, I.; Weiderpass, E.; Tjønneland, A.; Olsen, A.; Overvad, K.; Boutron-Ruault, M.C.; Clavel-Chapelon, F.; et al. Lifestyle, dietary factors, and antibody levels to oral bacteria in cancer-free participants of a European cohort study. Cancer Causes Control 2013, 24, 1901-1909.

5. Tanis, T.; Cincin, Z.B.; Gokcen-Rohlig, B.; Bireller, E.S.; Ulusan, M.; Tanyel, C.R.; Cakmakoglu, B. The role of components of the extracellular matrix and inflammation on oral squamous cell carcinoma metastasis. Arch. Oral Biol. 2014, 59, 1155-1163.

6. Zhu, K.; Li, G.J.; Sun, P.; Wang, R.; Qian, Y.; Zhao, X. In vitro and in vivo anti-cancer activities of Kuding tea (Ilex kudingcha C.J. Tseng) against oral cancer. Exp. Ther. Med. 2014, 7, 709-715.

7. Zhao, X.; Wang, Q.; Li, G.J.; Chen, F.; Qian, Y.; Wang, R. In vitro antioxidant, anti-mutagenic, anti-cancer and anti-angiogenic effects of Chinese Bowl tea. J. Func. Food. 2014, 7, 590-598.

8. Zhao, X.; Deng, X.X.; Park, K.Y.; Qiu, L.H.; Pang, L. Purple bamboo salt has anticancer activity in TCA8113 cells in vitro and preventive effects on buccal mucosa cancer in mice in vivo. Exp. Ther. Med. 2013, 5, 549-554.

9. Zhao, X.; Wang, Q.; Qian, Y.; Pang, L. Cassia tora L. (Jue-ming-zi) has anticancer activity in TCA8113 cells in vitro and exerts anti-metastatic effects in vivo. Oncol. Lett. 2013, 5, 1036-1042.

10. Zhao, X.; Ju, J.H.; Kim, H.M.; Park, K.Y. Antimutagenic activity and in vitro anticancer effects of bamboo salt on HepG2 human hepatoma cells. J. Environ. Pathol. Toxicol. Oncol. 2013, 32, 9-20. 
11. Zhao, X.; Pang, L.; Li, J.; Song, J.L.; Qiu, L.H. Apoptosis inducing effects of Kuding tea polyphenols in human buccal squamous cell carcinoma cell line BcaCD885. Nutrients 2014, 6, 3084-3100.

12. Zhao, X.; Kim, S.Y.; Park, K.Y. Bamboo salt has in vitro anticancer activity in HCT-116 cells and exerts anti-metastatic effects in vivo. J. Med. Food 2013, 16, 9-19.

13. Matsumiya, T.; Hayakari, R.; Narita, N.; Ito, R.; Kon, T.; Kubota, K.; Sakaki, H.; Yoshida, H.; Imaizumi, T.; Kobayashi, W.; et al. Role of type I- and type II-interferon in expression of melanoma differentiation-associated gene-5 in HSC-3 oral squamous carcinoma cells. Biomed. Res. 2014, 35, 9-16.

14. Garcia-Contreras, R.; Scougall-Vilchis, R.J.; Contreras-Bulnes, R.; Kanda, Y.; Nakajima, H.; Sakagami, H. Effects of TiO2 nano glass ionomer cements against normal and cancer oral cells. Vivo 2014, 28, 895-907.

15. Yamamura, T.; Matsumoto, N.; Matsue, Y.; Okudera, M.; Nishikawa, Y.; Abiko, Y.; Komiyama, K. Sodium butyrate, a histone deacetylase inhibitor, regulates lymphangiogenic factors in oral cancer cell line HSC-3. Anticancer Res. 2014, 34, 1701-1708.

16. Baddela, V.S.; Baufeld, A.; Yenuganti, V.R.; Vanselow, J.; Singh, D. Suitable housekeeping genes for normalization of transcript abundance analysis by real-time RT-PCR in cultured bovine granulosa cells during hypoxia and differential cell plating density. Reprod. Biol. Endocrinol. 2014, 12, doi:10.1186/1477-7827-12-118.

17. Zhang, R.; Yang, D.; Zhou, C.; Cheng, K.; Liu, Z.; Chen, L.; Fang, L.; Xie, P. $\beta$-actin as a loading control for plasma-based Western blot analysis of major depressive disorder patients. Anal. Biochem. 2012, 427, 116-120.

18. Morgan, C.W.; Julien, O.; Unger, E.K.; Shah, N.M.; Wells, J.A. Turning on caspases with genetics and small molecules. Methods Enzymol. 2014, 544, 179-213.

19. Zhao, Y.; Lei, M.; Wang, Z.; Qiao, G.; Yang, T.; Zhang, J. TCR-induced, PKC- $\theta$-mediated NF- $\kappa \mathrm{B}$ activation is regulated by a caspase-8-caspase-9-caspase-3 cascade. Biochem. Biophys. Res. Commun. 2014, 450, 526-531.

20. Yan, X.; Tian, J.; Wu, H.; Liu, Y.; Ren, J.; Zheng, S.; Zhang, C.; Yang, C.; Li, Y.; Wang, S. Ginsenoside rb1 protects neonatal rat cardiomyocytes from hypoxia/ischemia induced apoptosis and inhibits activation of the mitochondrial apoptotic pathway. Evid. Based Complement. Alternat. Med. 2014, 2014, doi:10.1155/2014/149195.

21. Tsagarakis, N.J.; Drygiannakis, I.; Batistakis, A.G.; Kolios, G.; Kouroumalis, E.A. A concentration-dependent effect of ursodeoxycholate on apoptosis and caspases activities of HepG2 hepatocellular carcinoma cells. Eur. J. Pharmacol. 2010, 640, 1-7.

22. Zhu, L.; Shan, L.J.; Liu, Y.J.; Chen, D.; Xiao, X.G.; Li, Y. Ursodeoxycholic acid induces apoptosis of hepatocellular carcinoma cells in vitro. J. Dig. Dis. 2014, 15, 684-693.

23. Lee, S.; Braun, C.R.; Bird, G.H.; Walensky, L.D. Photoreactive stapled peptides to identify and characterize BCL-2 family interaction sites by mass spectrometry. Method. Enzymol. 2014, 544, 25-48.

24. Choi, H.J.; Yee, S.B.; Park, S.E.; Im, E.; Jung, J.H.; Chung, H.Y.; Choi, Y.H.; Kim, N.D. Petrotetrayndiol A induces cell cycle arrest and apoptosis in SK-MEL-2 human melanoma cells through cytochrome c-mediated activation of caspases. Cancer Lett. 2006, 232, 214-225. 
25. Park, J.A.; Lee, K.Y.; Oh, Y.J.; Kim, K.W.; Lee, S.K. Activation of caspase-3 protease via a $\mathrm{Bcl}$-2-insensitive pathway during the process of ginsenoside Rh2-induced apoptosis. Cancer Lett. 1997, 121, 73-81.

26. Silke, J.; Vucic, D. IAP family of cell death and signaling regulators. Method. Enzymol. 2014, 545, 35-65.

27. Hui, K.K.; Kanungo, A.K.; Elia, A.J.; Henderson, J.T. Caspase-3 deficiency reveals a physiologic role for Smac/DIABLO in regulating programmed cell death. Cell Death Differ. 2011, 18, 1780-1790.

28. Park, J.S.; Shin, D.Y.; Lee, Y.W.; Cho, C.K.; Kim, G.Y.; Kim, W.J.; Yoo, H.S.; Choi, Y.H. Apoptotic and anti-metastatic effects of the whole skin of Venenum bufonis in A549 human lung cancer cells. Int. J. Oncol. 2012, 40, 1210-1219.

29. Deng, L.; Lu, Y.; Zhao, X.; Sun, Y.; Shi, Y.; Fan, H.; Liu, C.; Zhou, J.; Nie, Y.; Wu, K.; Fan, D.; Guo, X. Ran GTPase protein promotes human pancreatic cancer proliferation by deregulating the expression of survivin and cell cycle proteins. Biochem. Biophys. Res. Commun. 2013, 440, 322-329.

30. Wei, S.B.; Cao, Y.F.; Wang, Y. Effect of Neiyi Kangfu suppository on expressions of cytochrome $\mathrm{C}$ and survivin in ectopic and eutopic endometrium in rats with endometriosis. Chin. J. Integr. Tradi. West. Med. 2008, 28, 139-141.

31. Kearns, M.T.; Barthel, L.; Bednarek, J.M.; Yunt, Z.X.; Henson, P.M.; Janssen, W.J. Fas ligand-expressing lymphocytes enhance alveolar macrophage apoptosis in the resolution of acute pulmonary inflammation. Am. J. Physiol. Lung Cell Mol. Physiol. 2014, 307, 62-70.

32. Guo, C.L.; Yang, X.H.; Cheng, W.; Xu, Y.; Li, J.B.; Sun, Y.X.; Bi, Y.M.; Zhang, L.N.; Wang, Q.C. Expression of Fas/FasL in CD8+ T and CD3+ Foxp3+ Treg cells-Relationship with apoptosis of circulating CD8+ T cells in hepatocellular carcinoma patients. Asian Pac. J. Cancer Prev. 2014, 15, 2613-2618.

33. Zhang, T.; Wang, X.; He, D.; Jin, X.; Guo, P. Metformin sensitizes human bladder cancer cells to TRAIL-induced apoptosis through mTOR/S6K1-mediated downregulation of c-FLIP. Anticancer Drug. 2014, 25, 887-897.

34. Chen, Z.; Sangwan, V.; Banerjee, S.; Chugh, R.; Dudeja, V.; Vickers, S.M.; Saluja, A.K. Triptolide sensitizes pancreatic cancer cells to TRAIL-induced activation of the death receptor pathway. Cancer Lett. 2014, 348, 156-166.

35. Sheikh, M.S.; Huang, Y. Death receptor activation complexes: It takes two to activate TNF receptor 1. Cell Cycle 2003, 2, 550-552.

36. Chaudhary, P.M.; Eby, M.T.; Jasmin, A.; Kumar, A.; Liu, L.; Hood, L. Activation of the NF-kappaB pathway by caspase 8 and its homologs. Oncogene 2000, 19, 4451-4460.

37. Zhao, X.; Sun, P.; Qian, Y.; Suo, H.Y.D. candidum has in vitro anticancer effects in HCT-116 cancer cells and exerts in vivo anti-metastatic effects in mice. Nutr. Res. Pract. 2014, 8, 487-493.

(C) 2015 by the authors; licensee MDPI, Basel, Switzerland. This article is an open access article distributed under the terms and conditions of the Creative Commons Attribution license (http://creativecommons.org/licenses/by/4.0/). 